\title{
POR QUE PENÉLOPE MENCIONA HELENA? RELENDO ODISSEIA, XXIII, 209-230
}

\author{
André Malta* * Universidade de \\ São Paulo.
}

\begin{abstract}
RESUMO: Que grau de complexidade podemos atribuir à caracterização de Penélope na Odisseia? Em que medida essa complexidade decorre da apresentação de uma figura cujas ações valorosas combinam-se com a insinuação de intenções dúbias? Este artigo dá continuidade ao que foi exposto em outro texto, "Penélope e a arte da indecisão na Odisseia", no qual busquei, muito sinoticamente, abordar a atuação da esposa de Odisseu do canto I ao XXI. Aqui, abordo exclusivamente o canto XXIII, onde ocorre sua última, e talvez mais memorável, participação. $\mathrm{Na}$ minha leitura, a menção que Penélope faz aí a Helena, em sua conversa com Odisseu, ativa as mesmas camadas contraditórias vistas em passos anteriores, responsáveis pela riqueza de seu caráter.
\end{abstract}

PALAVRAS-CHAVE: Penélope; Helena; personagem; Odisseia.

\section{WHY DOES PENELOPE MENTION HELEN? REREADING ODYSSEY XXIII, 209-230}

\begin{abstract}
What kind of complexity can one attach to Penelope's character in the Odyssey? Does it follow from a combination of faithful actions and dubious intentions? This paper must be read along with another essay I wrote some years ago, "Penélope e a arte da indecisão na Odisseia", in which I approached her behavior from Book 1 to Book 21. Here I deal only with Book 23, where she appears for the last time in the poem. In my reading, when she mentions Helen in her conversation with Odysseus, she activates the same contradictory layers that can be seen in previous passages of the Odyssey and that are responsible for the richness of her character.
\end{abstract}

KEYWORDS: Penelope; Helen; character; Odyssey.

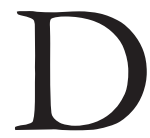

epois de receber o comando de Telêmaco, no canto XXI, para que retornasse a seus aposentos, para onde efetivamente se dirige, chorando Odisseu e recebendo um sono suave de Atena (v. 343-358), Penélope só volta a aparecer no canto XXIII da Odisseia. É Euricleia quem lhe comunica a volta do 
marido - que o mendigo na verdade era ele, disfarçado - e a matança dos pretendentes (v. 5-9, 26-31 e 40-57), narrada para nós no canto imediatamente anterior. Penélope, que, significativamente, nunca dormira tão bem desde que Odisseu havia partido (v. 15-19), inicialmente descrê do que ouve (v. 11-24, 35-38 e 59-67), embora o narrador nos informe da sua alegria (ekhárē, v. 32). Euricleia menciona então a prova irrefutável, a cicatriz que ela mesma vira ao lavar-lhe os pés (v. 70-79), mas Penélope continua reticente (v. 81-84), com seu "ânimo sempre incrédulo" (thumòs ápistos, v. 72). O narrador, intervindo mais extensamente no diálogo, nesse momento nos diz que ela "muito ponderava" (pollà hórmaine) entre "interrogar o marido amado à distância" ou "beijar-lhe a cabeça" (v. 8587) - e aqui a chamada "focalização embutida" parece apontar para o reconhecimento, que ela apenas quer retardar, simulando dúvida. ${ }^{1}$ No entanto, logo em seguida o mesmo narrador nos informa que ela "não sabia (agnósaske) se era ele, tais os farrapos que vestia" (v. 95), o que nos leva a crer que, sob o disfarce de mendigo, dificilmente Odisseu poderia ser reconhecido por ela (mas ainda assim nos perguntamos: e a semelhança física notada antes por Penélope e Euricleia, no canto XIX?). ${ }^{2}$ Repreendida por Telêmaco por se manter afastada do marido "com ânimo resistente" (tetléti thumôi, v. 100), ela responde:

Meu filho, dentro do peito meu ânimo está aturdido:

nem dizer palavra alguma consigo, nem perguntar nada, nem para sua cara olhar de frente. Mas se de fato é Odisseu e à sua casa chega, nós dois com certeza reconheceremos um ao outro melhor: nós temos sinais - os quais, ocultados dos outros, nós dois sabemos.

(Odisseia, XXIII, 105-110)

Quem retruca a ela dessa vez não é Telêmaco, mas o próprio Odisseu:

Telêmaco, deixa sim tua mãe dentro do palácio testar (peirázein) a mim, e depressa já refletirá melhor.

(Odisseia, XXIII, 113-114)

Como os comentadores da Odisseia já apontaram, teste e reconhecimento aparecem aqui como elementos que marcam a identificação entre Odisseu e Penélope - ou a homophrosúne, "co-pensamento", que ele mesmo falara (para Nausícaa) que deveria haver

\footnotetext{
${ }^{1}$ Irene de Jong fala em "uso altamente refinado da focalização" em seu A narratological commentary on the Odyssey, 2011, p. 500-501. Ver também Adriane Duarte, Cenas de reconhecimento na poesia grega, 2012, p. 166-167. Todas as traduções, do grego e das demais obras citadas, são de minha autoria.

${ }^{2}$ É Philip Harsh quem chama a atenção para esse detalhe no seu artigo; sua proposta, no entanto, é de que Penélope suspeitava sim da identidade do mendigo, apesar de não haver nenhuma indicação concreta por parte de Homero. Essa verdade latente seria descortinada por Anfimedonte em sua fala a respeito da ação conjunta de marido e mulher (Odisseia, XXIV, 167-168), com o conhecimento dos mortos sendo assim manipulado pelo poeta. Ver o seu "Penelope and Odysseus in Odyssey XIX"; Harsh, 1950, p. 19-21.
} 
entre marido e mulher. ${ }^{3}$ A hesitação e o excesso de cautela correspondem a características destacadas em Odisseu por Atena (XIII, 332-336); o "ânimo resistente" de Penélope (XXIII, 100 e 168) é o mesmo do esposo, com o Ciclope (IX, 435) e com os pretendentes (XVIII, 135 e XXIV, 163); o "coração de ferro" (XXIII, 172) remete aos "olhos de ferro" do marido diante das lágrimas dela, Penélope (XIX, 211-212); e, finalmente, a vontade de pôr à prova, mesmo quando aparentemente isso não é mais necessário, relaciona-se ao que fará o próprio Odisseu com o pai (XXIV, 220-240). ${ }^{4}$

O teste da cama, porém, não é o primeiro a que Penélope submete Odisseu: ela já fizera isso no canto XIX, perguntando ao mendigo sobre informações precisas em relação às roupas do marido (v. 215-219). Naquela provação, porém, ela anunciava claramente sua intenção; aqui, embora Odisseu saiba que será posto à prova através de sinais, ele acaba sendo pego de surpresa pela informação de que o leito foi removido. Ou seja: no momento em que é testado, ele não tem controle total da situação como tinha antes, o que serve para, de certo modo, inverter a balança da inteligência no jogo entre marido e mulher. ${ }^{5}$

É importante lembrar que, quando finalmente chega a cena do teste seguido de reconhecimento (v. 164-240), Odisseu já foi transformado por Atena (156-163), o que nos lança mais claramente ainda dentro do espírito do jogo esperto característico do casal. A provação, ao mesmo tempo em que trabalha com a ideia da imobilidade da cama como símbolo da permanência do casamento, como aponta Sheila Murnaghan, traz no comando dado por Penélope a Euricleia - de que o leito fosse removido - o "risco da traição", a "sugestão de infidelidade", que tanto encoleriza Odisseu. Mas é exatamente porque não compartilhou de sua intimidade com nenhum outro homem que Penélope pode apostar nesse sinal - a fixidez da cama - como sinal do reconhecimento de Odisseu, o único a compartilhar do segredo dessa construção singular:

É somente porque ela permite que ninguém mais saiba sobre a imobilidade da cama, podendo assim usar isso para testá-lo, que esse segredo representa a identificação de Odisseu e a fidelidade de Penélope. É somente em função do que Penélope tem em mente, que aquilo que Odisseu descreve como sêma, "marca", da cama (Odisseia, XXIII, 188 e 202) pode funcionar como sêma de outro tipo: um sinal que a convence da identidade dele (Odisseia, XXIII, 206). ${ }^{6}$

\footnotetext{
${ }^{3}$ Ver também a identificação dos dois indicada por Atena em Odisseia, II, 274. Segundo Sarah Bolmarcich, o termo só é usado para a relação de amizade entre homens (como acontece com Telêmaco e Pisístrato, Odisseia, XV, 195-198), e a aplicação extraordinária a um casal - num poema com forte antagonismo homem / mulher - só reforça, antecipadamente, a ligação entre Odisseu e Penélope, em contraste com casais como Agamêmnon - Clitemnestra e Helena - Menelau. Ver o seu artigo "Homophrosune in the Odyssey"; Bolmarcich, 2001.

${ }^{4}$ Katz, 1991, p. 164.

${ }^{5}$ Duarte, 2012, p. 168-169.

${ }^{6}$ Murnaghan, 1987, p. 140-141.
} 
No fim, a reunião do casal depende desse leito imóvel, índice não só da fidelidade feminina, mas também do patrocínio da deusa Atena, devido ao fato de a cabeceira ter sido construída com perícia (v. 197), pelo próprio marido, a partir de um "arbusto verdejante de oliveira", depois reduzido a seu tronco (v. 190, 195-196, 204): essa oliveira nos faz assim lembrar a "vara" ou "estaca" da mesma planta usada por Odisseu em suas astúcias contra o Ciclope (Odisseia, IX, 319-320, 378, 382 e 394).

É nesse momento então que a ideia de traição, insinuada por Penélope na cena - mas dela de certo modo já afastada desde antes, através da figura da serva Melanto, que faz o que a senhora não faz e se deita com Eurímaco (XVIII, 320-339 e XIX, 65-95) -, termina por se associar a Helena, ela sim desavisada em relação ao engano de um homem:

Comigo, Odisseu, não brigues tu - de resto sempre o mais ponderado dentre os homens. Os deuses nos deram dor, sim, eles que se agastaram com nós dois ficarmos juntos a gozar a juventude, e à soleira da velhice.

Comigo agora não fiques colérico ou indignado, porque primeiro, ao te ver, eu não te saudei assim...

É que meu ânimo sempre dentro do querido peito temia que um dos mortais com palavras me enganasse, chegando aqui: pois são muitos que planejam vis proveitos!

Nem mesmo a argiva Helena, a que é nascida de Zeus, teria ao leito deitado com um homem de outras terras se antes soubesse que os filhos belicosos dos acaios iam trazê-la de novo pra casa, pra cara pátria.

Foi sim um deus que a incitou a ter ultrajante ação: até então, não lançara no ânimo a perdição odiosa, da qual primeiro o pesar também nos veio. Mas agora, após já relatares os sinais nítidos do nosso leito, observado por nenhum outro mortal senão só por ti, por mim, e ainda uma serva apenas (Actóris, a que meu pai me deu ao vir para cá, a que as portas pra nós dois guardou do compacto quarto), já persuades o meu ânimo, por mais áspero que seja.

(Odisseia, XXIII, 209-230)

A menção à mulher de Menelau e ex-amante de Páris parece sem sentido nesse passo: por que desculpar a figura por excelência da mulher infiel, vítima da átè divina, quando o que se quer destacar é precisamente a fidelidade a toda prova? Por que tratar com aparente simpatia uma traidora? ${ }^{8}$

\footnotetext{
${ }^{7}$ Ver Felson-Rubin, 1994, p. 30, e também Katz, 1991, p. 130-132.

${ }^{8}$ Para a visão de que Penélope é simpática com Helena e a desculpa, ver Platt, 1899, p. 382-384 e, mais recentemente, Saïd, 2011, p. 307-308: "temos uma mulher fiel desculpando o comportamento de uma adúltera"; Jones, 1988, p. 214: "livra Helena de culpa pela Guerra de Troia ao atribuir a
} 
Mas é preciso ter atenção ao contexto e ao modo - nem sempre linear - com que Homero coordena as ideias. O ponto central é este: a partir do verso 209, com o reconhecimento já tendo ocorrido mediante os sinais da cama, Penélope quer se justificar pela demora em abraçar o marido, ou, em outras palavras, por seu excesso de cautela. Desse verso 209 ao verso 230, a sequência do raciocínio dela pode ser parafraseada da seguinte maneira: a guerra de Troia os separou por longo tempo e os fez sofrer; Penélope ficou sujeita aos enganos de outros homens, aos quais respondia com desconfiança e resistência; Helena, ao contrário, cedeu a um estrangeiro, sem saber que provocaria uma terrível guerra, a qual traria sofrimento tanto para Odisseu quanto para sua esposa; mas agora ela, Penélope, estava convencida da identidade dele, não precisando mais manter a incredulidade. A traição de Helena - cega - está no princípio da guerra e dos sofrimentos em ílion (que ela, a esposa de Odisseu, chama por três vezes de "Horrílion");" a não-traição de Penélope, por sua vez, corresponde a um comportamento astuto, atento ao engano, de quem é capaz de aprender com esses acontecimentos do passado. Vejam-se as palavras de Philip Harsh:

A defesa de Penélope centra-se nos enganos de deuses e homens, e nas consequências monstruosas de um erro como o de Helena. Helena não conseguiu antecipar o futuro - que sua união com Páris não era permanente e traria dor para si mesma e para muitos outros (...). A comparação com Helena, latente ao longo do poema (por exemplo, em Odisseia, XI, 436-439), é aqui bastante adequada, e a defesa de Penélope sai enfraquecida se omitirmos esses versos (tal como aconselham os críticos, tanto antigos como modernos). ${ }^{10}$

Nesse sentido, Helena não é propriamente desculpada e tratada com simpatia por Penélope: a átée "perdição", apenas a associa ao engano, sem implicar uma causalidade exclusivamente divina ou o fim da percepção de sua responsabilidade. O movimento é mais de contraste do que de aproximação: Helena, precipitada, foi vítima da apátē; ela, Penélope, exatamente para não incorrer na mesma desgraça, teve que se mostrar absolutamente atenta e desconfiada.

No entanto, acredito que incorreríamos em erro semelhante ao dos partidários da "exoneração" de Helena se considerássemos a passagem livre de qualquer problema: admitindo-se simplesmente que Penélope não está isentando Helena de culpa, exatamente porque se contrapõe a ela em prudência e perspicácia - ainda assim, não ficaríamos com um contraexemplo perturbador, capaz de manchar a figura de Penélope no momento em que se

responsabilidade aos deuses"; Heubeck, 1992, p. 336-337: "tenta fornecer uma visão simpática de Helena, mostrando que suas ações foram resultado de uma interferência divina"; e de Jong, 2011, p. 557-559: "Penélope desculpa Helena" com motivação "exclusivamente divina".

${ }^{9}$ Em grego, Kakoílion (Odisseia, XIX, 260 e 597, e XXIII, 19); cf. o Dúsparis Páris da Ilíada (III, 39 e XIII, 769).

${ }^{10}$ Harsh, 1950, p. 6. Para uma defesa tipicamente analista da supressão dos versos 218-224, ver Monro, 1901, p. 252. Para uma visão geral de como os analistas trataram o passo, ver Katz, 1991, p. 182-185. 
defende? Esse tipo de abordagem mais complexa vem sendo proposta, sob óticas diferentes, desde pelo menos o comentário de William Stanford, da década de 40, quando já dizia:

O arrazoado de Penélope é obscurecido por conta dos motivos conflitantes: por um lado, ela quer citar Helena como exemplo das desastrosas consequências de se confiar num estranho, mas, por outro, não quer condená-la como pessoa. ${ }^{11}$

Segundo Stanford, o fato de a comparação não ser feita aí por uma terceira pessoa (como é o caso da comparação com Clitemnestra, em XI, 440-453 e XXIV, 192-202) produz certo "embaraço", que dificulta a compreensão do passo. Seguindo por aí, podemos rever o que dissemos e admitir que talvez haja uma contradição na fala de Penélope: ao mesmo tempo em que não absolve Helena e a usa sim como figura oposta, a esposa de Odisseu a trata com certa simpatia - simpatia reforçada pelo fato de que a analogia surge em sua própria boca.

A já citada Sheila Murnaghan, em seu livro renovador, já defendia que essa atenção para com Helena talvez pudesse ser associada a uma "suscetibilidade ao desejo" por parte de Penélope, aproximando a esposa de Odisseu das irmãs traidoras (Helena e Clitemnestra) no momento mesmo da diferenciação. ${ }^{12}$ Depois dela, mas de forma mais elaborada, Marylin Katz, aplicando o conceito de "indeterminação de sentido", propôs que, ao evocar o exemplo de Helena, Penélope acabava por produzir uma "fusão de traição com fidelidade". ${ }^{13}$ Num artigo de 1997, Hardy Fredricksmeyer chegava a uma conclusão parecida: após mostrar que há um contraste entre as duas mulheres ${ }^{14} \mathrm{e}$ nenhuma exoneração de responsabilidade, ${ }^{15} \mathrm{ele}$ admite que há no trecho um "tom de algo inapropriado", que contribui para a posição ambígua de Penélope, entre adultério e fidelidade - esta reafirmada na voz da mulher de Odisseu, mas aquele outro comportamento sendo objeto de insinuações por parte da voz narrativa geral, de "Homero" ${ }^{16}$ Finalmente, Mario Zambarbieri, em seu extenso comentário à Odisseia, embora afirme que "entre as duas mulheres não há paralelo, mas contraste" e que "é difícil encontrar um exemplo de imprevidência mais contrário à cautela demonstrada por Penélope do que o comportamento passional de Helena", deve reconhecer, ao final, que Penélope é simpática a Helena, "porque sente o quanto ela mesma esteve próxima do perigo". ${ }^{17}$

A partir desses apontamentos, parece-me inegável que o movimento geral da passagem é - paradoxalmente - o de uma simpática incriminacãa de Helena por Penélope, movimento este que faz parte de uma estratégia maior no poema que consiste em, numa formulação resumida, pintar uma Penélope inequivocamente fiel em suas ações (a “circunspecta" Penélope), mas talvez não tão fiel em suas intenções. No plano superficial,

\footnotetext{
${ }^{11}$ Stanford, 1947, vol. 2, p. 401; grifo meu.

${ }^{12}$ Murnaghan, 1987, p. 142.

${ }^{13}$ Katz, 1991, p. 186-187. Duarte, 2012, p. 173-174, vai contra essa leitura.

${ }^{14}$ Fredricksmeyer, 1997, p. 489.

${ }^{15}$ Fredricksmeyer, 1997, p. 491.

${ }^{16}$ Fredricksmeyer, 1997, p. 491.

${ }^{17}$ Zambarbieri, 2004, p. 656-657.
} 
a esposa de Odisseu livra aqui a própria cara, mas, ao fazê-lo por meio de e contra Helena, ativa num plano profundo a misoginia que percorre todo o poema, de tal forma que acaba por respingar na nossa heroína a fama de que quer se apartar... Dentro desse espírito, quero destacar rapidamente alguns elementos da cena que contribuem para essa leitura, não deixando, no entanto, de apontar para outros temas importantes para o conjunto da Odisseia. Dois tópicos principais merecem atenção: o da esperteza (que se associa ao engano) e o da atuação divina no sentido de conferir sofrimentos aos homens.

Vejamos o primeiro tópico, relativo à astúcia e à dissimulação. É interessante notar como Penélope abre esse discurso destacando o caráter "ponderado" de Odisseu (no original, o verbo pépnumai, v. 210), trabalhando com uma ideia que, como se sabe, vem tradicionalmente associada a Telêmaco, por meio do epíteto pepnuménos. Esse jeito reflexivo de herói que Penélope quer destacar estabelece, por sua vez, uma conexão com o comportamento cauteloso da própria esposa, a qual, ao contrário do que diz de Helena (v. 220), é presciente e capaz de atentar para os desdobramentos de uma eventual ação indevida sua. O curioso é que essa nova identificação entre o casal vem perturbada pelo receio - explicitado por ela - de que fosse enganada (verbo apaphiskô) com palavras por homens que pensam em maus proveitos, em kakà kérdea (v. 216-217). A perturbação se deve ao fato de que Odisseu não só agiu dissimuladamente em relação à esposa, ocultando-lhe a verdade, mas também de que a "mente poliproveitosa" (nóon polukerdéa, XIII, 255), ou o saber de "muitos proveitos" (kérdea pollá, XIX, 285), é uma característica marcante do herói. É verdade que seus propósitos não são vis - ao contrário do que acontece com seus antagonistas, os soberbos pretendentes -, mas aqui podemos trabalhar com a sugestão de leitura fornecida por Hanna Roisman, que detectou nas palavras da mulher uma "mágoa com a falta de prontidão de Odisseu em se revelar" ${ }^{18}$ Dentro desse motivo da dissimulação, a referência a Helena ainda nos faria pensar - segundo Roisman - num possível reconhecimento (o sempre debatido reconhecimento...) do Odisseu-mendigo por parte de Penélope, tal como ele, Odisseu-mendigo, fora antes identificado pela esposa de Menelau (mas dela se esquivou com kerdosúnē: IV, 249-251). Veja-se o que diz a estudiosa:

Ao dizer que temia um impostor, Penélope manda a bola de volta para o lado de Odisseu, sugerindo que era responsabilidade dele garantir que ela seria capaz de identificá-lo (...). Além do mais, a censura torna-se ainda mais enfática com a menção a Helena, a única a reconhecer Odisseu no seu disfarce de mendigo, em Troia (...). A associação talvez sugira que ela reconheceu o marido, mas esse fato não o livra da responsabilidade de se revelar a ela. A afirmação de Penélope é, como sempre, indireta e sutil, mas eloquente: sua conduta é medida e cautelosa, análoga, de um modo agudo, à maneira como Odisseu a tratou. ${ }^{19}$

\footnotetext{
${ }^{18}$ Roisman, 1987, p. 63.

${ }^{19}$ Roisman, 1987, p. 65.
} 
De acordo com Roisman, de certa maneira Odisseu fez o que Penélope mais temia: "ele assumiu a forma de outra pessoa e usou palavras para convencê-la de uma identidade falsa; ao se empenhar em seu disfarce, Odisseu é como aqueles muitos homens que planejam kakà kérdea". ${ }^{20}$ Analisando mais detidamente os usos de kérdea em Homero e especificamente na Odisseia, ela conclui que "por meio dessa notável afirmação, aparentemente bastante inocente, Penélope revela um genuíno descontentamento com o modo pelo qual foi tratada por Odisseu". ${ }^{21}$

Portanto, a partir desses elementos, é possível propor que, com essas palavras: 1. Penélope reforça a harmonia com o marido, ambos cautelosos, de tal modo que a astúcia dele deve contribuir para que entenda o uso da astúcia por parte dela também; repare-se, nesse sentido, no uso do dual, noìn, "nós dois", no começo e no fim (v. 211 e 229); na posição enfática do "nosso leito" (v. 226); e na cumplicidade sublinhada pelo conhecimento único que tinham da cama, cumplicidade que não se quebra, mas antes se reforça, com a referência à escrava que "guardava as portas do compacto quarto" (v. 228-229); e 2. que, ao mesmo tempo em que isso tudo reforça a harmonia do casal, a própria presença da astúcia aponta, de um lado, para a possibilidade de um ressentimento da esposa em relação ao marido (porque este teria "abusado" do engano), e, de outro, para o fato de ela mesma poder ter agido (e ainda agir) para com ele dissimuladamente, ao ocultar o que de fato sabia e sentia. Novamente a Penélope aparentemente submissa e passiva esconde uma mulher mais complexa, capaz de planejar "proveitos" como o renomado marido. Se ela se deixa, no fim, persuadir, não é menos verdade que, ao colocar o marido à prova com os sinais do leito, é ela que o controla - e este seu discurso subsequente de desculpa e justificativa pode bem fazer parte ainda desse mesmo movimento.

O segundo tópico diz respeito à responsabilização dos deuses: ele é importante porque se conecta tanto à átē de Helena quanto ao infortúnio de que foram vítimas Penélope e Odisseu. Em relação a Helena, vimos que a sua "ultrajante ação" (érgon aeikés) foi incitada por um deus (v. 222), o que não impede que, em grego, o sujeito da oração seguinte oculto - seja a própria Helena: "até então, [Helena] não lançara no ânimo a perdição" (v. 223). Sabemos que, em Homero, dentro do esquema da chamada "dupla motivação", não é incomum essa atribuição de um feito, em chocante sequência, ora ao plano divino, ora ao humano. Se essa "perdição" (átê), como se viu, não tira de Helena a responsabilidade pelo que foi feito; se, em outras palavras, o "pesar" (pénthos, v. 224) que atingiu o casal de Ítaca foi causado simultaneamente pela mulher infiel e por uma divindade (Afrodite) que a guiou (e que ainda a guiava explicitamente, como se sabe, no canto III da Iliada), ficamos com a pergunta: que ação humana concorreu para a "dor" (oïzún, v. 210) a que Penélope faz referência na abertura do seu discurso?

A construção parece anelar, o que nos faria concluir que o pénthos do verso 224 está retomando o ö̈zun do verso $210 .{ }^{22}$ Roisman vê aí a presença do tema da "recusa divina", assim

\footnotetext{
${ }^{20}$ Roisman, 1987, p. 65.

${ }^{21}$ Roisman, 1987, p. 67-68.

${ }^{22}$ Roisman, 1987, p. 61.
} 
como o faz Vincenzo Di Benedetto, que lembra, oportunamente, da fala anterior de Filécio (XX, 199-203). ${ }^{23}$ Poderíamos sim ficar apenas com a ideia de que esse "freio" divino tem, na abertura do discurso, um valor mais geral e indeterminado, vindo a ser especificado no momento em que se menciona Helena, quando se revela sua natureza complicada: o crime, causado por uma força divina (mas não só por ela), tem como contrapartida um sofrimento mandado pelos deuses (e que não atinge apenas o criminoso). Mas acho significativo o fato de, nesse ponto da fala de Penélope, a alusão ao sofrimento enviado de cima vir enquadrada pelo receio de um comportamento colérico de Odisseu (mếmoi skúzeu, v. 209; mé moi khốeo, v. 213) - que ela justamente quer evitar evocando, como vimos, o caráter tipicamente "ponderado" do herói (v. 210). Se não me engano, apenas George Dimock chamou atenção para esse detalhe, o que não causa espanto, porque em seu livro esse estudioso insiste em explorar as conexões, no poema, entre o nome de Odisseu e as noções de "ódio" e "dor". ${ }^{24}$ Ora, sabemos que a afirmação programática de Zeus no canto I - passo complexo e debatido, que não posso abordar aqui - estabelece que os homens têm dores "além do quinhão" (bupèr móron) por culpa própria (v. 32-34). À luz disso, seria possível imaginar, dentro do tom sutilmente crítico da passagem divisado por Roisman, que Penélope estaria em parte responsabilizando Odisseu - o Odisseu marcado desde o nascimento pelo "odiar" / "ser odiado" (verbo odússomai: XIX, 406-409 e I, 60-62; V, 339-340 e 423; XIX, 275-276) - por sua volta tardia, que os privou do gozo supremo da juventude? Deixo a pergunta sem resposta, mas adianto apenas que, em minha visão, o poema oferece algumas pistas eloquentes sobre uma caracterização complexa e menos "heroica" de Odisseu, caracterização essa que passa por um olhar seu retrospectivo-autocrítico, entre os cantos IX e XII, e em cuja base está uma relação nem sempre linear entre glória (kléos) / astúcia (mêtis) / identidade. Aqui quero apenas sugerir que, em relação ao esposo, Penélope pode então estar adotando - junto com a acolhida - um tom sinuoso de responsabilização, que faz com que, além dela mesma, também ele se associe ao (contra)exemplo de Helena.

É possível argumentar que Penélope, de sua perspectiva humana, trata Helena de modo "simpático" exatamente porque seu olhar não é o de Zeus, e que os homens em geral tendem a dar mais peso à ação divina (como o próprio Cronida nos indica). Pode-se objetar ainda que há uma diferença radical entre o crime de Egisto mencionado no canto I e este de Helena, tal qual Penélope o menciona: Egisto sabia antecipadamente o que o esperava no caso de matar Agamêmnon (v. 35-43), enquanto Helena, por sua vez, só agiu como agiu porque não teve a possibilidade da presciência. Em relação a esse segundo ponto, pode-se argumentar que a presciência só agrava a posição de Egisto, mas que se trata de uma exceção: o erro tipicamente humano é como o de Helena - o homem age cegamente e só percebe depois as consequências. $\mathrm{O}$ acesso a informações prévias, privilegiadas, quando acontece, tem em geral a função de reafirmar a cegueira (exatamente porque informar-se antes não equivale a saber

${ }^{23}$ Di Benedetto, 2010, p. 1188-1190.

${ }^{24}$ G. Dimock, The unity of the Odyssey; Dimock, 1989, p. 319-320. No entanto, suas tentativas de ligar Odusseús a ö̈zus e odúnè me parecem, do ponto de vista linguístico e nos contextos propostos, pouco convincentes. 
mais; pelo contrário, só acentua o menor saber). Em relação ao primeiro ponto, é possível chegarmos sim à conclusão de que o olhar mais "simpático" de Penélope radica justamente numa espécie de entendimento da natureza humana, jamais isenta de responsabilidade, mas sujeita a forças que a ultrapassam, que merecem ser destacadas.

Com base nesses elementos - que devem ser reforçados por outros mais, e por uma visão geral da caracterização de Penélope ao longo da Odisseia -, quis propor, na trilha do que já foi antes indicado por alguns estudiosos, que a esposa de Odisseu, no momento em que reafirma e defende seu caráter de mulher confiável, talvez fale ainda de forma um pouco traiçoeira, com uma retórica esperta, como se pudesse haver alguma dissimulação de sua parte. Nesse contexto, a estratégia do texto de fazê-la trazer à baila uma comparação com Helena (a Helena contraditoriamente traiçoeira e fiel aos acaios, nas memórias apresentadas no canto IV, capaz tanto de reconhecer Odisseu no passado quanto Telêmaco no presente) desempenha um papel fundamental: através dessa figura distante e próxima, Penélope, em sua "apologia", na mesma medida em que reafirma sua integridade moral, abre espaço para que pensemos que sabe manipular a linguagem de um modo sofisticado e dúbio.

\section{REFERÊNCIAS}

BOLMARCICH, S. Homophrosine in the Odyssey. Classical Philology, v. 96, p. 205-213, 2001.

DI BENEDETTO, V. Omero: Odissea. Milano: BUR, 2010.

DIMOCK, G. The unity of the Odyssey. Amherst: University of Massachusetts, 1989.

DUARTE, A. Cenas de reconbecimento na poesia grega. Campinas: Editora da Unicamp, 2012.

FELSON-RUBIN, N. Regarding Penelope. From character to poetics. Princeton: Princeton University Press, 1994.

FREDRICKSMEYER, H. Penelope 'polutropos': the crux at Odyssey 23.218-22. American Journal of Philology, v. 118, n. 4, p. 487-497, 1997.

HARSH, P. Penelope and Odysseus in Odyssey XIX. American Journal of Philology, v. 71, n. 1, p. 1-21, 1950.

HEUBECK, A. Books XXIII-XXIV in HEUBECK, A., RUSSO, J., FERNANDEZGALIANO, M. (ed.). A commentary on Homer's Odyssey, Volume III, Books XVII-XXIV. Oxford: Clarendon Press, 1992. p. 311-418.

JONES, P. Homer's Odyssey. A commentary based on the translation of Richmond Lattimore. London: Bristol Classics Press, 1988.

de JONG, I. A narratological commentary on the Odyssey. Cambridge: Cambridge University Press, 2011.

KATZ, M. Penelope's renown. Meaning and indeterminacy in the Odyssey. Princeton: Princeton University Press, 1991. 
MALTA, A. Penélope e a arte da indecisão na Odisseia. Nuntius Antiquus, v. 8, n. 1, p. 7-28, 2012. MONRO, D. Homer's Odyssey. Books XIII-XXIV. Oxford: Clarendon Press, 1901.

MURNAGHAN, S. Disguise and recognition in the Odyssey. Princeton: Princeton University Press, 1987.

PLAT'T, A. Notes on the Odyssey. Classical Review, v. 13, n. 8, p. 382-384, 1899.

ROISMAN, H. Penelope's indignation. Transactions of the American Philological Association, v. 117 , p. $59-68,1987$.

SAÏD, S. Homer and the Odyssey. Translated by Ruth Webb. Oxford: Oxford University Press, 2011.

STANFORD, W. The Odyssey of Homer. 2 vols. London: St. Martin Press, 1947.

ZAMBARBIERI, M. L'Odissea com'è. Lettura critica. Vol. II: canti XIII-XXIV. Milano: Edizioni Universitarie di Lettere Economia Diritto, 2004. 